\title{
Regional gastrointestinal contractility parameters using the wireless motility capsule: inter-observer reproducibility and influence of age, gender and study country
}

\author{
A. D. Farmer ${ }^{1,2,3}$ \\ A.-M. L. Wegeberg ${ }^{1,4}$ \\ B. Brock $^{5}$ \\ A. R. Hobson ${ }^{6}$ | \\ S. D. Mohammed ${ }^{2}$ \\ S. M. Scott ${ }^{2}$ \\ C. E. Bruckner-Holt ${ }^{3}$ \\ J. R. Semler ${ }^{7}$ \\ W. L. Hasler ${ }^{8}$ । \\ P. M. Hellström9 \\ A. M. Drewes ${ }^{1}$ \\ C. Brock ${ }^{1,10}$
}

\begin{abstract}
${ }^{1}$ Mech-Sense, Department of
Gastroenterology \& Hepatology, Aalborg and Clinical Institute, Aalborg University Hospital, Aalborg University, Denmark

${ }^{2}$ Neurogastroenterology Group, Centre for Neuroscience and Trauma, Blizard Institute, Wingate Institute of

Neurogastroenterology, Barts and the London School of Medicine \& Dentistry,

Queen Mary University of London, London, UK

${ }^{3}$ Department of Gastroenterology, University Hospitals of North Midlands, Stoke-on-Trent, UK

${ }^{4}$ School of Medicine and Health, Aalborg University, Aalborg, Denmark

${ }^{5}$ Department of Clinical Biochemistry, Aarhus University Hospital, Aarhus, Denmark

${ }^{6}$ The Functional Gut Clinic, London,UK

${ }^{7}$ Medtronic, Sunnyvale, CA, USA

${ }^{8}$ Division of Gastroenterology, University of Michigan Health System, Ann Arbor, MI, USA

${ }^{9}$ Department of Medical Sciences, Uppsala University, Uppsala, Sweden

${ }^{10}$ Department of Pharmacotherapy and Development, University of Copenhagen, Copenhagen, Denmark
\end{abstract}

\section{Correspondence}

Dr. A. D. Farmer, Wingate Institute of Neurogastroenterology, Barts and The London School of Medicine and Dentistry, London, London, UK.

Email: a.farmer@qmul.ac.uk

Funding information

Aalborg University; Novo Nordisk Foundation and the Research and Development Department; Uppsala University

\section{Summary}

Background: The wireless motility capsule concurrently measures temperature, $\mathrm{pH}$ and pressure as it traverses the gastrointestinal tract.

Aims: To describe normative values for motility/contractility parameters across age, gender and testing centres.

Methods: Healthy participants underwent a standardised wireless motility capsule assessment following an overnight fast and consumption of a meal of known nutritional content. Traces were divided into regions of interest and analysed using 2 software packages (MotiliGI and GIMS Data Viewer). Inter-observer agreement was independently assessed by 2 investigators.

Results: Normative data for motility/contractility parameters (maximum amplitude, mean peak amplitude, contraction frequency and motility index) are presented for 107 individuals (62 male, median age 40 years, range 18-78). MotiliGI-Gastric, small bowel and colonic maximal contraction amplitude correlated with age $(r=.24$, $P=.01 ; r=.22, P=.02$; and $r=.2, P=.04$ respectively). Small bowel motility index was higher in females than males $(150.4 \pm 12$ vs $122 \pm 7.6, P=.04)$. Inter-observer agreement was excellent for transit times, $\mathrm{pH}$ and contractility/motility parameters. GIMS Data viewer-Gastric, small bowel and colonic $\log _{e}$ motility index correlated with the respective area under the contraction curve, total contractions, sum of amplitudes and contraction frequency (all $r .35, P<.0003$ ) but not with transit times.

Conclusions: Our analysis provides normative data for motility/contractility parameters. Log motility index summarises a number of measures. In future, the measurement of contractile activity with the wireless motility capsule may potentially aid in the diagnosis of disease states such as visceral myopathic disorders. 


\section{1 | INTRODUCTION}

Gastrointestinal (GI) motility can be considered as movements within the digestive system and transit of contents across the absorptive and secretary surface. This process is coordinated and regulated through a complex circuitous interaction between a numbers of system including, but not limited to, the enteric, autonomic and central nervous systems. When aberrancies occur in any of these, it may result in disruption of the coordination of propulsive peristalsis, potentially leading to dysmotility and ultimately symptoms. ${ }^{1}$ However, dysmotility has been used to describe a plethora of abnormalities, which are not purely limited to alterations in transit but may also result in changes in GI sensorimotor activity. ${ }^{2}$

Currently, our understanding of $\mathrm{Gl}$ motility, both in health and disease, has been limited by the relative inaccessibility of certain portions of the $\mathrm{Gl}$ tract. ${ }^{3}$ Although several techniques are available to evaluate such regions, many of these primarily measure only transit times, although it is well recognised that these poorly predict symptoms. ${ }^{4}$ Technological developments, such as those seen with high-resolution manometric techniques, have facilitated the concurrent evaluation of both motility as well as contractility patterns. ${ }^{5,6}$ While these techniques are considered to be the gold standard, by definition they necessitate the placement of an intraluminal catheter which can cause a transient disturbance in the underlying regulatory neural systems that control motility. ${ }^{7}$ Furthermore, particularly for the assessment of large bowel function, studies need to be of relatively long duration ( $>24$ hours), can necessitate colonoscopy and sedation (that may potentially influence motility) and require the subject under study to be confined to the laboratory. ${ }^{8}$

Therefore, techniques that measure both contractility and motility that do not require an intraluminal catheter provide an alternative and more attractive method of describing normal and abnormal $\mathrm{Gl}$ physiology. ${ }^{5,9}$ To be clinically applicable, such techniques should be standardised, reproducible and easily interpretable as well as acceptable to the patient. In this regard, the wireless motility capsule has a number of salient advantages. ${ }^{10,11}$ For instance, it is minimally invasive, ambulatory and does not require exposure to ionising radiation. Additionally, the wireless motility capsule has been demonstrated to be sensitive and specific technique in measuring pan-enteric and regional transit is comparable to conventional methods and has robust normal ranges for transit times and $\mathrm{pH}^{.11-13}$ The wireless motility capsule has been approved for use in the USA by the Food and Drug Administration for investigating suspected delayed gastric emptying and chronic constipation. ${ }^{14}$ In addition to measuring temperature and $\mathrm{pH}$, the wireless motility capsule also measures intraluminal pressure as it traverses the $\mathrm{Gl}$ tract. ${ }^{10,14}$ However, this has received scant attention in the literature to date. Moreover, the inter-observer agreement of contractility measures has not been comprehensively described. ${ }^{15}$ The primary aim of this study was to define normative ranges for regional and contractility/motility measures. Our secondary aims were to evaluate the inter-observer agreement between transit times, $\mathrm{pH}$ profile and contractility/ motility parameters as well as investigating the co-relationship between these and the motility index.

\section{MATERIALS AND METHODS}

\section{1 | Study population}

The study population consisted of 109 healthy participants who underwent wireless motility capsule testing in studies performed in the UK (14/109), Sweden (22/109) and the USA (73/109). The data from the USA were collected during a multi-centre clinical trial evaluating $\mathrm{Gl}$ transit as measured by the wireless motility capsule in comparison to radio-opaque markers and has been published elsewhere. ${ }^{16}$ The data from Sweden were collected as part of the process for deriving normative transit values. ${ }^{12}$ The data from the UK were derived from the baseline recordings in healthy subjects of a clinical trial programme investigating the promotile drug camicinal. ${ }^{17}$ The respective Institutional Review Boards, or Ethical Committees, approved all studies at the study centres. Each participant provided written informed consent. Participants were included if they were between 18 and 80 years old, with no concurrent or past medical history of cardiovascular, endocrine, renal, gastroenterological, liver, respiratory or any other chronic disease or currently taking any medications (prescribed or over the counter). Participants were also required to have a normal bowel habit, defined as a complete spontaneous bowel movement at least once per 48 hours for the purposes of this study. Participants were excluded if there was a known absolute or relative contraindication to undergoing a wireless motility capsule study (such as previous GI surgery, clinical evidence of diverticulitis), if there was a history of Gl symptoms or if they had a body mass index $>35 \mathrm{~kg} / \mathrm{m}^{2}$, were pregnant or had a planned magnetic resonance imaging (MRI) procedure during the study. Participants were instructed to refrain from tobacco and alcohol use for 24 hours prior to wireless motility capsule ingestion and during the study period.

\section{2 | Wireless motility capsule}

The wireless motility capsule (SmartPill, Medtronic, Minneapolis, USA) has been described elsewhere. ${ }^{13,18}$ In brief, the wireless motility capsule system consists of an indigestible single-use capsule, an external portable data receiver, a docking station and bespoke display and analysis software. The wireless motility capsule contains 3 sensors: (1) a pH sensor capable of measuring $\mathrm{pH}$ in the range of 0.5 to $9.0 \mathrm{pH}$ units with an accuracy \pm 0.5 , (2) a pressure transducer capable of measuring pressures ranging from 0 to $350 \mathrm{~mm} \mathrm{Hg}$ with an accuracy of $\pm 5 \mathrm{~mm} \mathrm{Hg}$ below $100 \mathrm{~mm} \mathrm{Hg}$ and $\pm 10 \mathrm{~mm} \mathrm{Hg}$ at, or above, $100 \mathrm{~mm} \mathrm{Hg}$ and (3) a temperature sensor capable of measuring temperatures ranging from 25 to $49^{\circ} \mathrm{C}$ with an accuracy of $\pm 1^{\circ} \mathrm{C}$. After activation, calibration and ingestion, $\mathrm{pH}$, pressure and temperature are continuously measured as the wireless motility capsule traverses the GI tract. Data from the sensors are transmitted at $434 \mathrm{MHz}$ to the portable data receiver worn by the participants. 
Data are stored within the receiver and can be downloaded to a personal computer, using a USB docking station, for subsequent analysis.

\section{3 | Wireless motility capsule testing protocol}

After an overnight fast, participants ingested a standardised meal consisting of known nutritional content (SmartBar ${ }^{\circledR}$, Medtronic, Minneapolis, USA, $260-\mathrm{kcal}$, composed of $3 \%$ fat, $21 \%$ protein and $75 \%$ carbohydrate, $3 \%$ of which as fibre) with $50 \mathrm{~mL}$ of water. Following this meal, participants ingested the wireless motility capsule which had been previously calibrated and activated as per the manufacturer's instructions. Participants were then asked to refrain from eating for the next 6 hours and avoid strenuous physical activity. After 6 hours, participants were permitted to resume their daily activities and diet. During the recording period, participants were asked to record bowel movements, food intake/meal times, GI symptoms (if any) and sleeping times on the portable data receiver.

\subsection{Wireless motility capsule data analysis}

\subsection{1 | Definition of anatomical landmarks}

Each participant's wireless motility capsule data were downloaded onto a personal computer (Dell, Bracknell, Berkshire, UK) and analysed using the manufacturer supplied analysis software (MotiliGI, version 3.0.20, Medtronic, Minneapolis, USA). The Gl tract was divided into 3 regions based on the identification of stereotypical landmarks, based on $\mathrm{pH}$ and temperature measures, as per the method proposed by Sarosiek et al. ${ }^{19}$ In brief, the gastric region and gastric emptying time were defined from capsule ingestion, which is associated with a sharp temperature rise to $37^{\circ} \mathrm{C}$, until a steep $\mathrm{pH}$ rise (>3 pH units) from gastric baseline to a $\mathrm{pH}$ greater than $4.0 \mathrm{pH}$ units, reflecting passage across the pylorus. The small bowel region and small bowel transit time were defined as from this point until passage across the ileocaecal junction (ICJ), characterised a sustained drop in $\mathrm{pH}$ greater than $1 \mathrm{pH}$ unit, and sustained for at least $10 \mathrm{~min}$ utes. $^{18}$ Finally, the colonic region and colonic transit time were defined from this point until capsule expulsion, verified by a characteristic temperature drop from body temperature to room temperature, see Figure 1.

\subsubsection{Motility and contractility measures}

Motility and contractility measures were calculated using 2 pieces of proprietary software (MOTILIGI, version 3.0.20, and GIMS Data Viewer, version 3.0.0, Medtronic, Minneapolis, USA). MotiliGI - the contractility and motility measures provided by the software include maximum amplitude of contractions, mean peak amplitude of contractions, contractions per minute and the MI. The MI combines a number of pressure measures into one metric. The $\mathrm{MI}$ is determined according to the method proposed by Ouyang et al whereby the summation of the area under the amplitude curve for contractions about $10 \mathrm{~mm} \mathrm{Hg}$ above baseline, calculated as the amplitude of the reading multiplied by the duration of the reading divided by the time window and expressed in units of $\mathrm{mm} \mathrm{Hg*second/min-}$ ute. $^{20}$ This is equivalent to the sum of the amplitudes of all the contractions multiplied by their duration in a given segment, thus providing a time-based summary measure. MotiliGl is user friendly and provides a "wizard" which aids in the performance of semi-automated analysis. GIMS Data viewer provides total number of contractions, frequency of contractions, area under of the curve (AUC) of contractions, sum of amplitudes and $\log _{\mathrm{e}}$ MI. The AUC represents the integral of the contraction amplitudes over time. The $\log _{e} \mathrm{MI}$ is derived from the natural log of the (sum of amplitudes $x$ number of contractions +1 ) as determined by Camilleri et al in healthy individuals in whom concomitant antral manometry and scintigraphy was undertaken after ingestion of a radiolabelled solid and liquid meal. ${ }^{21}$ The software calculates $\log _{\mathrm{e}} \mathrm{Ml}$ over the segment of interest, ie, gastric, small bowel and colon, as previous studies have suggested that the cumulated slope is linear. ${ }^{22}$ The $\log _{\mathrm{e}} \mathrm{Ml}$ therefore provides amplitude-based summary measure. GIMS Data viewer has been designed for research use. Pan-enteric data are shown in the Data S1.

\section{5 | Inter-observer agreement}

Inter-observer agreement was assessed in all participants. Traces were independently analysed by 2 observers (ADF and $\mathrm{CBH}$ ).

\subsection{Statistical analysis}

The motility/contractility measures are summarised using the number of observations, mean and standard deviation. To evaluate the effect of gender, age and study country on the study endpoints, a multiple linear regression model was used. Reference ranges for the motility parameters were derived from the 5 th to 95 th percentiles. Agreement between observers was compared using the intra-class correlation coefficient, and Bland-Altman's limits of agreement. A 2-way, random effects, single measure intra-class correlation coefficient model was used and interpreted according to Yen et al. using the following criteria: $<0.40=$ poor, 0.40 $0.59=$ fair, $\quad 0.60-0.74=$ good,$\quad 0.75-1.00=$ excellent. $^{23}$ Limits of agreement includes both random error (precision) and systematic error (bias), providing a useful measure for comparing the difference between 2 observations and is expressed as a 95\% confidence interval of the difference. Correlational analyses were performed to investigate the contribution of contractility parameters to $\mathrm{MI}$ and transit times and are reported using Pearson's ( $r$ ) or Spearman's coefficient $\left(r_{s}\right)$ dependant on data distribution. Given that this analysis was exploratory, we did not correct for multiple testing. Two-tailed tests were used throughout. $P<.05$ was adopted as the criterion for statistical significance. All analyses were performed using proprietary software (STATA, Version 14, College Station, TX, USA). 


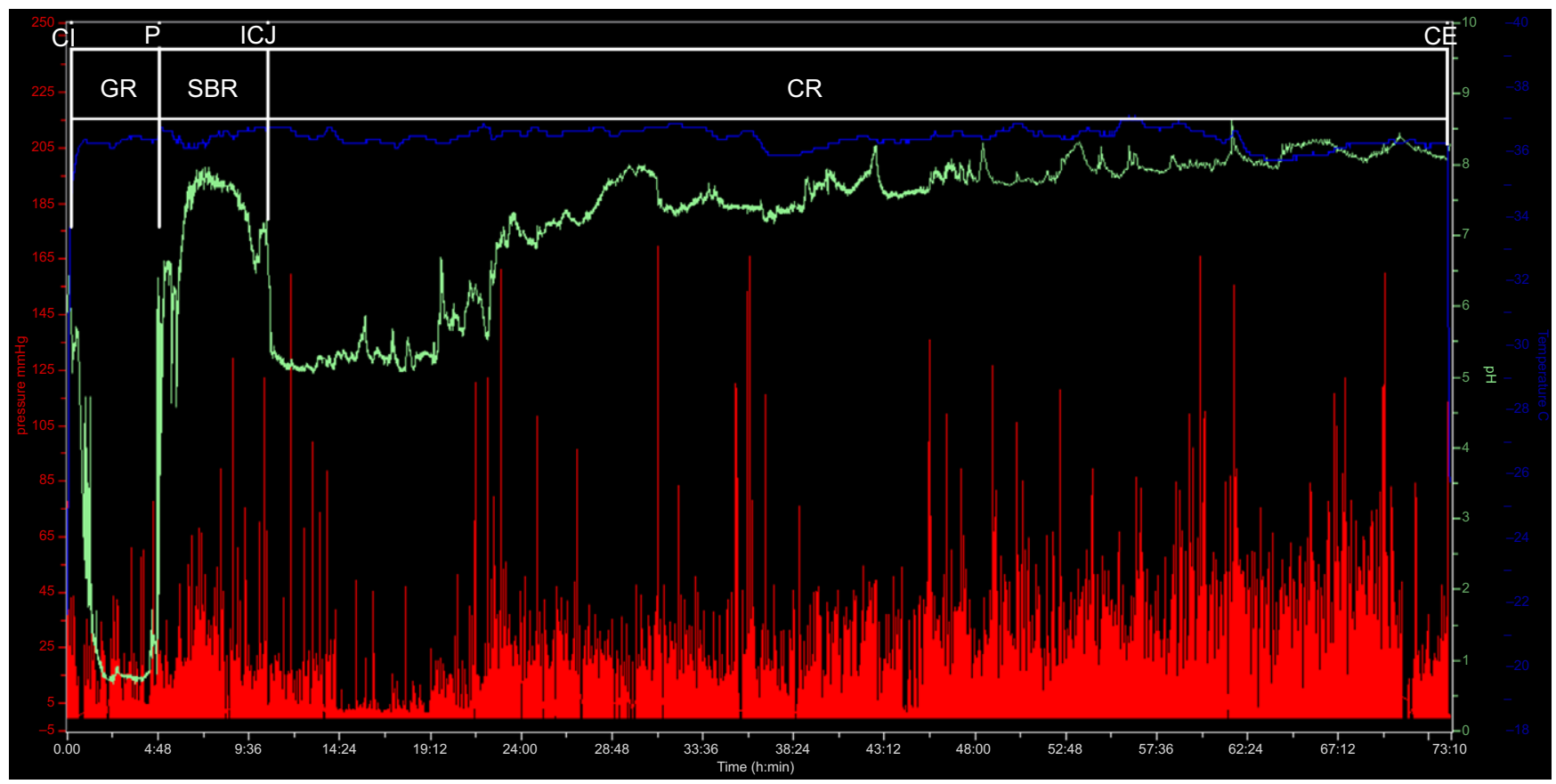

FIGURE 1 A typical tracing from a wireless motility capsule study. Time is recorded on the $x$-axis, pressure on the $y 1$-axis (red line) and $\mathrm{pH}$ on the $y 2$-axis (green line) and temperature (blue line). The gastric region (GR), small bowel region (SBR) and colonic region (CR) are illustrated. $\mathrm{Cl}$, capsule ingestion, $\mathrm{P}$, pylorus, ICJ, ileocaecal junction, $\mathrm{CE}$, capsule expulsion

\section{3 | RESULTS}

\section{1 | Participant characteristics}

A total of 109 individual wireless motility capsule data files were available. Of these, 2 were excluded due to major signal loss. Of the remaining 107 individual wireless motility capsule data files, 62 were male with a median age of 40 years, range 20-78, and 45 females with a median age of 38 years, range 18-74.

\subsection{Regional transit times and $\mathrm{pH}$ profile}

The mean gastric emptying time, small bowel transit time, colonic transit time and whole gut transit time were $194 \pm 118$ minutes, $262 \pm 107$ minutes, $1474 \pm 1112$ minutes and $1930 \pm 1158$ minutes respectively. There were no gender or country differences in gastric emptying time, small bowel transit time, colonic transit time and whole gut transit time. Age weakly positively correlated with prolonged wireless motility capsule $(r=.2, P=.04)$. The mean gastric, small bowel and colonic $\mathrm{pH}$ were $2.4 \pm 1.5,6.9 \pm 1$ and $6.8 \pm 1.1$ respectively. No gender, age or country differences were seen.

\section{3 | Motility/contractility measures-MotiliGI}

Motility and contractility measures derived from MotiliGl are shown in Table 1. Gastric $(r=.24, P=.01)$, small bowel $(r=.22, P=.02)$ and colonic ( $r=0.2, P=.04)$ maximal pressures correlated with age. The small bowel motility index was higher in females than males
(150.4 \pm 12 vs $122 \pm 7.6, P=.04)$. No other gender or country differences were evident. As expected based on their calculations, the respective gastric, small bowel and colonic motility indices correlated with the gastric $(r=.65, P<.0001)$, small bowel $(r=.6, P<.0001)$ and colonic $(r=.6, P<.0001)$ mean contraction amplitude. As expected based on their calculations, the gastric, small bowel and colonic MI correlated with their respective gastric $(r=.72$, $P<.0001)$, small bowel $(r=.8, P<.0001)$ and colonic $(r=.5$, $P<$.0001) mean contraction frequency. Gastric emptying time correlated with gastric $\mathrm{MI}(r=.4, P<.0001)$. Small bowel transit time and colonic transit time did not correlate with their respective $\mathrm{MI}$.

\section{4 | Motility/contractility measures_GIMS}

Motility and contractility measures derived from GIMS are shown in Table 2. The number of contractions within a segment positively correlated with gastric emptying time, small bowel transit time and colonic transit time $\left(r_{\mathrm{s}}=.36, P<.0001 ; r_{\mathrm{s}}=.64, P<.0001 ;\right.$ and $\left.r_{\mathrm{s}}=.74, P<.0001\right)$. The respective AUC correlated with gastric emptying time, small bowel transit time and colonic transit time $\left(r_{\mathrm{s}}=.63, P=.0003 ; r_{\mathrm{s}}=.51, P<.0001 ;\right.$ and $\left.r_{\mathrm{s}}=.69, P<.0001\right)$. As expected based on their calculations, gastric $\log _{e} \mathrm{Ml}$ correlated with gastric AUC, total contractions, sum of amplitudes and frequency $(r=.86 P=.0001 ; r=.87 \quad P=.0001 ; r=.88 P=.0001 ; r=.61$ $P=.0001$ respectively). Gastric emptying time did not correlate with gastric $\log _{\mathrm{e}} \mathrm{MI}$. Female gender was associated with a higher gastric $\log _{\mathrm{e}} \mathrm{Ml}(14 \pm 1.5$ vs $13.2 \pm 1.4, P=.002)$ but there was no association with age or country. As expected based on their calculation, small bowel $\log _{\mathrm{e}} \mathrm{MI}$ correlated with small bowel AUC, total 
TABLE 1 Normative regional wireless motility capsule motility/contractility data using MotiliGl showing all and gender-specific means, standard deviations, median and 5\%-95\% percentiles

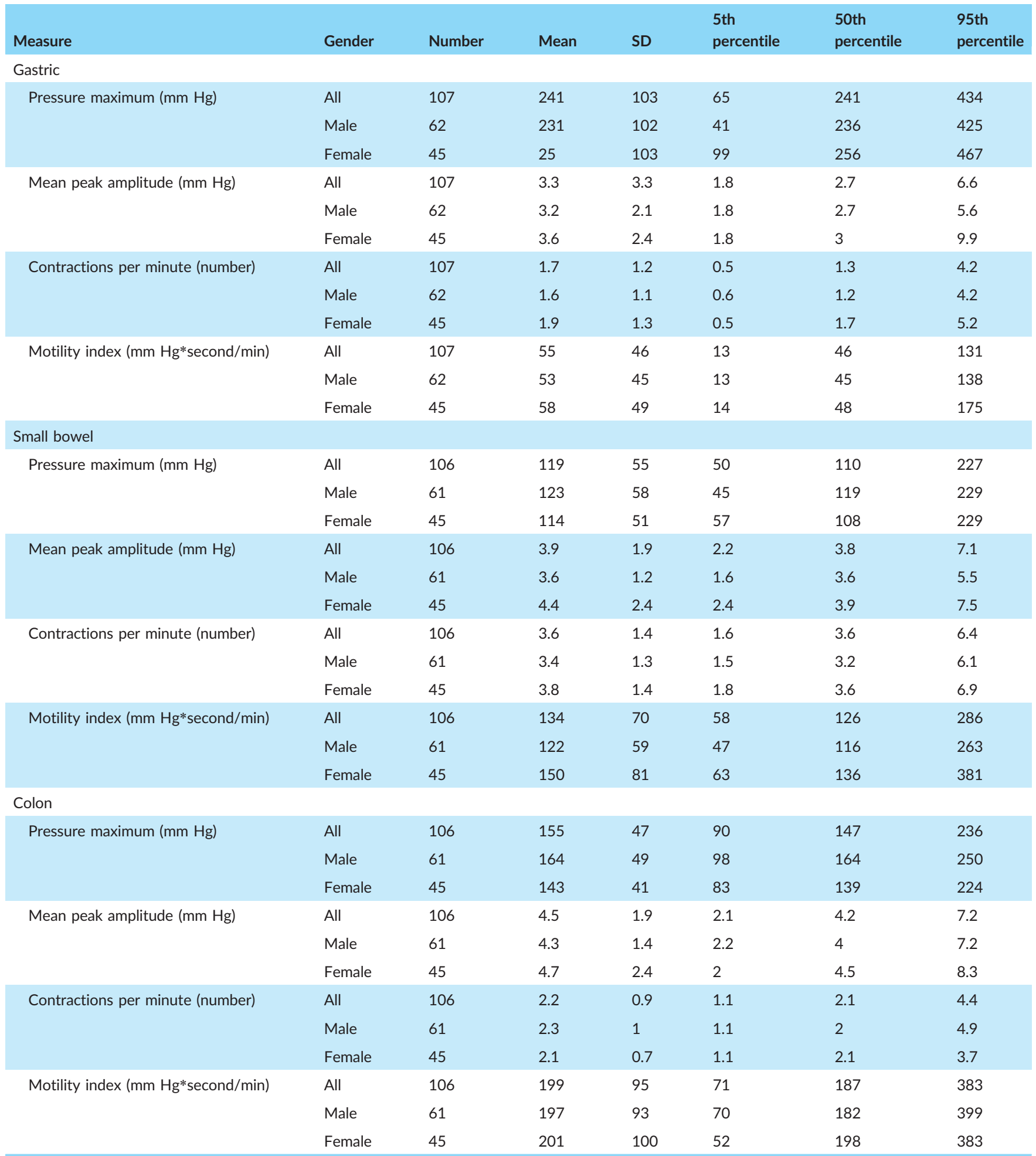

contractions, sum of amplitudes and frequency $(r=.84 P=.0001$; $r=.86 P=.0001 ; r=.91 P=.0001 ; r=.69 P=.0001$ respectively). Small bowel transit time did not correlate with small bowel $\log _{\mathrm{e}} \mathrm{MI}$. Gender, age or country was not associated with small bowel $\log _{e} \mathrm{MI}$. As expected based on their calculations, colonic $\log _{e} \mathrm{MI}$ correlated with colonic AUC, total contractions, sum of amplitudes and frequency $(r=.72 P=.0001 ; r=.87 \quad P=.0001 ; r=.85 \quad P=.0001 ;$ $r=.35 P=.0003$ respectively). Colonic transit time did not correlate with colonic $\log _{e} \mathrm{MI}$, and gender, age or country was not associated with colonic $\log _{\mathrm{e}} \mathrm{MI}$. 
TABLE 2 Normative regional wireless motility capsule motility/contractility data using GIMS showing all and gender specific means, standard deviations, median and 5\%-95\% percentiles

\begin{tabular}{|c|c|c|c|c|c|c|c|}
\hline Measure & Gender & Number & Mean & SD & 5th percentile & 50th percentile & 95th percentile \\
\hline \multicolumn{8}{|l|}{ Gastric } \\
\hline \multirow[t]{2}{*}{ Total contractions (number) } & All & 107 & 268 & 254 & 63 & 195 & 792 \\
\hline & Female & 45 & 353 & 330 & 94 & 231 & 1045 \\
\hline Contraction per minute (number) & All & 107 & 1.5 & 1.3 & 0.4 & 1.2 & 3.9 \\
\hline \multirow[t]{3}{*}{ Area under the curve } & All & 107 & 9619 & 8771 & 1544 & 6471 & 32629 \\
\hline & Male & 62 & 7659 & 6537 & 1503 & 5930 & 21296 \\
\hline & Female & 45 & 12400 & 10683 & 3418 & 7106.7 & 33492 \\
\hline Motility index-natural log & All & 107 & 13.6 & 1.5 & 11.3 & 13.6 & 16.3 \\
\hline \multirow{2}{*}{ Sum of amplitudes } & Male & 62 & 4458 & 3345 & 1367 & 3563 & 11418 \\
\hline & Female & 45 & 7466 & 6373 & 2311 & 4716.8 & 18689 \\
\hline \multicolumn{8}{|l|}{ Small bowel } \\
\hline \multirow[t]{3}{*}{ Total contractions (number) } & All & 106 & 781 & 417 & 242 & 729 & 1567 \\
\hline & Male & 61 & 741 & 395 & 229 & 677 & 1486 \\
\hline & Female & 45 & 837 & 445 & 287 & 851 & 1821 \\
\hline \multirow[t]{3}{*}{ Contraction per minute (number) } & All & 106 & 3.5 & 1.5 & 1.5 & 3.3 & 6.4 \\
\hline & Male & 61 & 3.3 & 1.5 & 1.5 & 2.9 & 6.3 \\
\hline & Female & 45 & 3.7 & 1.5 & 2 & 3.6 & 6.3 \\
\hline Motility index-natural log & Female & 45 & 16.1 & 1.1 & 14.2 & 16.3 & 17.9 \\
\hline \multirow[t]{3}{*}{ Sum of amplitudes } & All & 106 & 14485 & 8068 & 4505 & 13361 & 30628 \\
\hline & Male & 61 & 13737 & 7631 & 4450 & 12203 & 27088 \\
\hline & Female & 45 & 15545 & 8629 & 5494 & 14421 & 32458 \\
\hline \multicolumn{8}{|l|}{ Colon } \\
\hline \multirow[t]{3}{*}{ Total contractions (number) } & All & 106 & 622 & 489 & 87 & 497 & 820 \\
\hline & Male & 61 & 559 & 408 & 102 & 464 & 1377 \\
\hline & Female & 45 & 712 & 579 & 61 & 577 & 1717 \\
\hline \multirow[t]{3}{*}{ Contraction per minute (number) } & All & 106 & 0.6 & 0.3 & 0.2 & 0.5 & 1.3 \\
\hline & Male & 61 & 0.6 & 0.3 & 0.3 & 0.6 & 1.3 \\
\hline & Female & 45 & 0.5 & 0.2 & 0.1 & 0.5 & 0.9 \\
\hline \multirow[t]{3}{*}{ Area under the curve } & All & 106 & 107640 & 119598 & 9095 & 73696 & 375574 \\
\hline & Male & 61 & 94570 & 116647 & 9916 & 58201 & 265957 \\
\hline & Female & 45 & 126181 & 122638 & 5137 & 97202 & 402153 \\
\hline \multirow[t]{3}{*}{ Motility index-natural log } & All & 106 & 16 & 1.7 & 12.6 & 16.2 & 18.5 \\
\hline & Male & 61 & 15.9 & 1.6 & 12.9 & 15.9 & 18.1 \\
\hline & Female & 45 & 16.2 & 1.9 & 11.9 & 16.6 & 18.9 \\
\hline
\end{tabular}


TABLE 2 (Continued)

\begin{tabular}{|cllllrr} 
Measure & Gender & Number & Mean & SD & 5th percentile & 50th percentile \\
\hline Sum of amplitudes & All percentile & 106 & 26532 & 22376 & 3407 & 21587 \\
& Male & 61 & 23790 & 4138 & 4138 & 18597
\end{tabular}

\section{5 | Inter-observer agreement}

Inter-observer agreement was assessed all participants, Table 3. Intra-class correlation coefficient and limits of agreement showed excellent reproducibility for majority of the measures.

\section{DISCUSSION}

To date, this is the largest and most comprehensive dataset that describes normative regional and motility/contractility parameters using the wireless motility capsule. The wireless motility capsule has become a popular method for measuring transit times due to is minimally invasive nature in an ambulatory setting. However, normative data only exist with regard to only a proportion of the wireless motility capsule's capabilities, ie transit times and regional $\mathrm{pH}^{12}$ Despite this, the wireless motility capsule also provides direct measurements of regional motility/contractility measures, which may also be potentially more useful clinically in evaluating GI motility. Nevertheless, these have been largely ignored in the literature to date. In this study, we have shown that the regional $\log _{e} \mathrm{Ml}$ is a particularly useful summary measure of contractility parameters given its robust correlations with other regional measures such as AUC, total contractions, sum of amplitudes and contraction frequency. $\log _{\mathrm{e}} \mathrm{MI}$ as reported in this study, ie derived from the wireless motility capsule, is numerically similar to that reported using an intraluminal catheter. ${ }^{21}$ Furthermore, we demonstrate that many of these parameters have good inter-observer agreement. Notably, it is clear from many of the motility/contractility measures that there is a large variation in the normal ranges presumably reflecting the diversity of "normal" Gl tract physiology.

The GI tract is a complex organ, large parts of which are relatively inaccessible, thus making it a challenge to assess in detail. ${ }^{3} \mathrm{~A}$ number of other methods to assess transit times are currently available, such as scintigraphy, ${ }^{24}$ radio-opaque markers, ${ }^{25}$ the 3-D magnetic transit system, ${ }^{3} \mathrm{MRI}^{26}$ and the wireless motility capsule. ${ }^{15}$ However, transit times per se may represent a blunt tool for evaluating GI motility as abnormalities that lead to symptoms can be more subtle. ${ }^{3}$ Despite the functionality of the wireless motility capsule to record pressure as it traverses the Gl tract, the majority of studies to date have not presented these data, arguably due to at least 3 factors. Firstly, due to the lack of availability of normative data, secondly due to challenges in calculating/extracting these parameters and finally their relevance to symptoms. However, a recent study by Barshop et al demonstrated that duodenal area under the pressure curve was strongly and reproducibly associated with symptom severity in patients with both idiopathic and diabetic gastroparesis; these findings warrant confirmation in larger more homogenous patient groups. ${ }^{27}$ However, based on the normative data we present herein, the values that they report would be within the normative range for this metric, Table 2. Nevertheless, such detailed measures may provide alternative relevant physiological endpoints in clinical trials as it is well described that transit times are not optimal to correlate with symptoms. ${ }^{28}$ A number of techniques have been developed and studied over the last 50 years utilising a variety of free-floating capsule techniques including those containing radiopharmaceuticals and pressure sensors. ${ }^{29,30} \mathrm{~A}$ more recently developed method is the $3 \mathrm{D}$ transit system which, using an electromagnetic capsule, can delineate pan-enteric and regional $\mathrm{Gl}$ motility ${ }^{3}$. The marked advantage of this system is that the location, velocity and direction of travel of the capsule, relative to the receiver plate, is known at all times. ${ }^{4}$ While this is a minimally invasive and ambulatory technique, the interpretation is labour-intensive and has yet to be validated in a large cohort of healthy subjects and remains a research tool. ${ }^{3}$

There was little correlation between transit times and other contractility measures. These data suggest that regional contractility and transit times are not inextricably linked as measured using the wireless motility capsule. In a previous study reported by Hasler and colleagues, of 56 healthy controls and 36 constipated subjects, it was demonstrated that colonic pressure activity increased from the proximal to distal colonic segments in all groups. ${ }^{31}$ However, when considering those subjects with the most severe slow transit constipation, there was a marked reduction in this increase in pressure activity albeit not associated with transit times.

We have demonstrated that the inter-observer agreement was excellent for the majority of measures. This is in agreement with the report by Rao et al who have previously described the intra-class correlation coefficient for regional and whole gut transit times in 45 traces, composed of 10 healthy participants, 10 patients with gastroparesis and 25 patients with constipation. ${ }^{32}$ The authors demonstrated excellent intra-class correlation coefficients between 3 independent observers. However, this study, to the best of our knowledge, has only been published in abstract form and did not encompass other motility/contractility measures derived from the wireless motility capsule. Moreover, intra-class correlation coefficients in isolation cannot provide a complete picture of inter-observer agreement and should be accompanied by other parameters such as limits of agreement, as included in our study. ${ }^{33}$

The process of analysing wireless motility capsule traces using MotiliGl is relatively straightforward as it includes an analysis "wizard" which guides the clinician. While GIMS does not include this feature, it does have enhanced functionality and provides a more detailed analysis of wireless motility capsule traces in comparison to MotiliGI. Thus, we would propose for routine clinical practice that there is an inherent temporal advantage of using MotiliGl rather 
TABLE 3 Inter-observer agreement of wireless motility capsule parameters showing observer median and inter-quartile range (IQR), intraclass correlation coefficient (ICC) and Bland-Altman's 95\% limits of agreement (LOA)

\begin{tabular}{|c|c|c|c|c|}
\hline Measure & $\begin{array}{l}\text { Observer A (median } \\
\text { and (IQR)) }\end{array}$ & $\begin{array}{l}\text { Observer B (median } \\
\text { and (IQR)) }\end{array}$ & $\begin{array}{l}\text { ICC ( } 95 \% \text { confidence } \\
\text { interval) }\end{array}$ & $\begin{array}{l}\text { Delta mean } \\
\text { (LOA) }\end{array}$ \\
\hline \multicolumn{5}{|l|}{ Gastric } \\
\hline Mean peak amplitude (mm Hg) & $2.7(2.3-3.5)$ & $2.8(2.4-3.5)$ & $0.99(0.99-0.99)$ & $0.08 \pm 0.1$ \\
\hline Contractions per minute & $1.3(1-2.1)$ & $1.3(1-2.1)$ & $0.96(0.91-0.99)$ & $-0.02 \pm 0.05$ \\
\hline Median $\mathrm{pH}$ & $2(1.2-3.7)$ & $2(1.2-3.7)$ & $0.99(0.99-0.99)$ & $-0.03 \pm 0.05$ \\
\hline \multicolumn{5}{|l|}{ Small bowel } \\
\hline Pressure maximum (mm Hg) & $110(83-141)$ & $109.9(84-141)$ & $0.99(0.99-0.99)$ & $-0.4 \pm 1.5$ \\
\hline Mean peak amplitude (mm Hg) & $3.8(3-4.3)$ & $3.9(3.1-4.3)$ & $0.99(0.99-0.99)$ & $-0.01 \pm 0.1$ \\
\hline Median $\mathrm{pH}$ & $7(6.6-7.4)$ & $7(6.7-7.4)$ & $0.99(0.99-0.99)$ & $-0.02 \pm 0.1$ \\
\hline \multicolumn{5}{|l|}{ Colon } \\
\hline Pressure maximum (mm Hg) & $147(118-184)$ & $147.1(117.8-183.9)$ & $0.99(0.99-0.99)$ & $-0.1 \pm 0.8$ \\
\hline Mean peak amplitude (mm Hg) & $4.2(3.5-5.2)$ & $4.2(3.5-5.2)$ & $0.99(0.99-0.99)$ & $-0.1 \pm 0.08$ \\
\hline Contractions per minute & $2.1(1.7-2.6)$ & $2.1(1.7-2.6$ & $0.99(0.99-0.99)$ & $-0.1 \pm 0.07$ \\
\hline Motility index & $187(128-267)$ & $188(129-265)$ & $0.99(0.99-0.99)$ & $-0.8 \pm 2.5$ \\
\hline Transit time & $1129(850-1987)$ & 1129 (850-1987) & $0.93(0.87-0.93)$ & $0.4 \pm 3$ \\
\hline Median $\mathrm{pH}$ & $6.9(6.5-7.3)$ & $6.9(6.5-7.3)$ & $0.99(0.99-0.99)$ & $-0.03 \pm 0.06$ \\
\hline
\end{tabular}

than GIMS. For gastric emptying time, colonic transit time and whole gut transit time, both Wang et al and Diaz-Tartera et al have demonstrated a strong correlation between the results derived from manual evaluation of wireless motility capsule traces and those reported by an automated analysis from MotiliGl suggesting that such an analysis is robust for clinical practice. ${ }^{12,34}$ In both of these studies, the agreement between the automated assessment of small bowel transit time was lower than the other transit measures arguably due to the relative difficulty of identification of the ICJ.

This study is not without limitations. In contrast to high-resolution manometry, the absolute interpretation of parameters derived from the wireless motility capsule is limited by the fact that it is currently not possible to detect a wave front, which represents a propulsive peristaltic pattern. Given that the wireless motility capsule is essentially a nonstatic "free-floating" pressure, $\mathrm{pH}$ and temperature transducer, the absolute clinical applicability of this normative dataset is limited to luminal pressures and transit times, but cannot detect the actual propagated pressure waves considered to be the primary mechanism for propulsive motility. Therefore, it could be cogently argued that the phasic contractile measurements delineated by the wireless motility capsule do not significantly add to the information of regional transit that can be measured by radio-opaque markers and/or scintigraphy. Although whole gut transit time can be measured with radio-opaque markers, which correlate reasonably well with wireless motility capsule derived transit times, the wireless motility capsule does offer the advantage of providing a regional motility profile, encompassing the entirety of the GI tract in a single ambulatory investigation. ${ }^{15}$ In the clinical environment, whether any of these measures robustly and reproducibly associate with symptoms remains to be seen. The current study was undertaken using a standardised test meal, and while this improves external validity with respect to the normative data, no inferences can be made to these values with respect to other meals of differing nutritional content. A further limitation of our study was that we did not control for the individual female's stage of their menstrual cycle as this may influence Gl motility. ${ }^{35}$ We had previously shown that female gender was associated with longer gastric emptying time, colonic transit time and whole gut transit time, ${ }^{12}$ although we did not demonstrate any associations between gender and transit times in this study. The reasons for this difference are unclear. Finally, the mean peak amplitudes were lower than we would have expected in comparison to previously reported stationary catheter studies ${ }^{36,37}$ and may limit the identification of pathologically low amplitudes of contractions, such as what is seen in connective tissue disorders such as scleroderma. ${ }^{38}$ In order to address this in future studies, an alternative approach which would be to use maximal amplitudes although further studies in clinical populations are needed.

In summary, this comprehensive analysis of the motility/contractility data provides normative motility/contractility data for the wireless motility capsule. Notably the $\log _{e} \mathrm{MI}$ provides a summary 
measure of many of these parameters. The measurement of contractile activity with the wireless motility capsule may advance our understanding of novel pharmacological agents ${ }^{17}$ and potentially in the diagnosis of disease states association with alterations in contractile amplitude, such as what is seen in visceral myopathic disorders.

\section{ACKNOWLEDGEMENTS}

Declaration of personal interests: John $\mathrm{R}$ Semler is an employee of Medtronic. S Mark Scott and William L Hasler have previously received funding from the SmartPill Corporation. None of the other authors have any relevant conflicts of interest.

Declaration of funding interests: $C B$ received funding from the Talent Programme, Aalborg University. ADF was supported by the Danish Diabetes Academy founded by the Novo Nordisk Foundation and the Research and Development Department, University Hospitals of North Midlands. PMH was funded by Uppsala University. Some of the data from healthy participants were derived from studies supported by the SmartPill Corporation. We acknowledge the role of Professor Braden Kuo and Satish Rao in collecting some of the healthy participant data.

\section{AUTHORSHIP}

Guarantor of the article: Dr Adam D Farmer, PhD, FRCP.

Author contributions: Anne-Marie L Wegeberg and Caroline Bruckner Holt were responsible for data extraction, statistical analysis, drafting of the manuscript and critical revision of the manuscript for important intellectual content. Sahar D Mohammed and S Mark Scott were data extraction, critical revision of the manuscript for important intellectual content. Anthony R Hobson, William L Hasler, Per M. Hellström and John R Semler were responsible for data acquisition and critical revision of the manuscript for important intellectual content. Brigitte Brock and Asbjørn Mohr Drewes contributed to technical or material support; study supervision; and critical revision of the manuscript for important intellectual content. Christina Brock, Adam D Farmer were responsible for manuscript preparation, statistical analysis, study supervision and critical revision of the manuscript for important intellectual content. All authors have approved the final version of the paper.

\section{ORCID}

A. D. Farmer (iD http://orcid.org/0000-0003-1902-2640

P. M. Hellström (iD http://orcid.org/0000-0001-8428-0772

C. Brock iD http://orcid.org/0000-0002-3381-1884

\section{REFERENCES}

1. Kloetzer L, Chey WD, McCallum RW, et al. Motility of the antroduodenum in healthy and gastroparetics characterized by wireless motility capsule. Neurogastroenterol Motil. 2010;22:527-533.e117.
2. Barshop K, Kuo B. Connecting the dots between gastrointestinal motility and symptoms using wireless motility capsule testing. Dig Dis Sci. 2015;60:1120-1122.

3. Gronlund D, Poulsen JL, Sandberg TH, et al. Established and emerging methods for assessment of small and large intestinal motility. Neurogastroenterol Motil. 2017;29. doi: 10.1111/nmo.13008

4. Camilleri M, Thorne NK, Ringel Y, et al. Wireless pH-motility capsule for colonic transit: prospective comparison with radiopaque markers in chronic constipation. Neurogastroenterol Motil. 2010;22:874-882. e233.

5. Segui S, Drozdzal M, Zaytseva E, et al. Detection of wrinkle frames in endoluminal videos using betweenness centrality measures for images. IEEE J Biomed Health Inform. 2014;18:1831-1838.

6. Dinning PG, Scott SM. Novel diagnostics and therapy of colonic motor disorders. Curr Opin Pharmacol. 2011;11:624-629.

7. Farmer $A D$, Coen SJ, Kano $M$, et al. Psychological traits influence autonomic nervous system recovery following esophageal intubation in health and functional chest pain. Neurogastroenterol Motil. 2013;25:950-e772.

8. Dinning PG, Carrington EV, Scott SM. The use of colonic and anorectal high-resolution manometry and its place in clinical work and in research. Neurogastroenterol Motil. 2015;27:1693-1708.

9. Camilleri M, Bharucha AE, di Lorenzo C, et al. American Neurogastroenterology and Motility Society consensus statement on intraluminal measurement of gastrointestinal and colonic motility in clinical practice. Neurogastroenterol Motil. 2008;20:1269-1282.

10. Farmer AD, Scott SM, Hobson AR. Gastrointestinal motility revisited: the wireless motility capsule. United European Gastroenterol J. 2013;1:413-421.

11. Maqbool S, Parkman HP, Friedenberg FK. Wireless capsule motility: comparison of the SmartPill GI monitoring system with scintigraphy for measuring whole gut transit. Dig Dis Sci. 2009;54:2167-2174.

12. Wang YT, Mohammed SD, Farmer AD, et al. Regional gastrointestinal transit and $\mathrm{pH}$ studied in 215 healthy volunteers using the wireless motility capsule: influence of age, gender, study country and testing protocol. Aliment Pharmacol Ther. 2015;42:761-772.

13. Cassilly D, Kantor S, Knight LC, et al. Gastric emptying of a nondigestible solid: assessment with simultaneous SmartPill $\mathrm{pH}$ and pressure capsule, antroduodenal manometry, gastric emptying scintigraphy. Neurogastroenterol Motil. 2008;20:311-319.

14. Hasler WL. The use of SmartPill for gastric monitoring. Expert Rev Gastroenterol Hepatol. 2014;8:587-600.

15. Saad RJ. The Wireless Motility Capsule: a One-Stop Shop for the Evaluation of GI Motility Disorders. Curr Gastroenterol Rep. 2016;18:14.

16. Rao SS, Kuo B, McCallum RW, et al. Investigation of colonic and whole-gut transit with wireless motility capsule and radiopaque markers in constipation. Clin Gastroenterol Hepatol. 2009;7:537-544.

17. Hobson R, Farmer AD, Dewit $O E$, et al. The effects of camicinal, a novel motilin agonist, on gastro-esophageal function in healthy humans-a randomized placebo controlled trial. Neurogastroenterol Motil. 2015;27:1629-1637.

18. Zarate N, Mohammed SD, O'Shaughnessy E, et al. Accurate localization of a fall in $\mathrm{pH}$ within the ileocecal region: validation using a dual-scintigraphic technique. Am J Physiol Gastrointest Liver Physiol. 2010;299:G1276-G1286

19. Sarosiek I, Selover KH, Katz LA, et al. The assessment of regional gut transit times in healthy controls and patients with gastroparesis using wireless motility technology. Aliment Pharmacol Ther. 2010;31:313-322.

20. Ouyang A, Sunshine AG, Reynolds JC. Caloric content of a meal affects duration but not contractile pattern of duodenal motility in man. Dig Dis Sci. 1989;34:528-536.

21. Camilleri M, Brown ML, Malagelada JR. Relationship between impaired gastric emptying and abnormal gastrointestinal motility. Gastroenterology. 1986;91:94-99. 
22. Camilleri M, Malagelada JR, Brown ML, Becker G, Zinsmeister AR. Relation between antral motility and gastric emptying of solids and liquids in humans. Am J Physiol. 1985;249:G580-G585.

23. Yen M, Lo LH. Examining test-retest reliability: an intra-class correlation approach. Nurs Res. 2002;51:59-62.

24. Abell TL, Camilleri M, Donohoe K, et al. Consensus recommendations for gastric emptying scintigraphy: a joint report of the American neurogastroenterology and motility society and the society of nuclear medicine. Am J Gastroenterol. 2008;103:753-763.

25. Rao SS, Rattanakovit K, Patcharatrakul T. Diagnosis and management of chronic constipation in adults. Nat Rev Gastroenterol Hepatol. 2016;13:295-305.

26. Alyami J, Spiller RC, Marciani L. Magnetic resonance imaging to evaluate gastrointestinal function. Neurogastroenterol Motil. 2015;27:16871692.

27. Barshop K, Staller K, Semler J, Kuo B. Duodenal rather than antral motility contractile parameters correlate with symptom severity in gastroparesis patients. Neurogastroenterol Motil. 2015;27:339-346.

28. Hasler WL. Gastroparesis: pathogenesis, diagnosis and management. Nat Rev Gastroenterol Hepatol. 2011;8:438-453.

29. Holdstock DJ, Misiewicz JJ, Smith T, Rowlands EN. Propulsion (mass movements) in the human colon and its relationship to meals and somatic activity. Gut. 1970;11:91-99.

30. Thorburn HA, Carter KB, Goldberg JA, Finlay IG. Does ispaghula husk stimulate the entire colon in diverticular disease? Gut. 1992;33:352356.

31. Hasler WL, Saad RJ, Rao SS, et al. Heightened colon motor activity measured by a wireless capsule in patients with constipation: relation to colon transit and IBS. Am J Physiol Gastrointest Liver Physiol. 2009;297:G1107-G1114.

32. Rao SC, Valestin J, Attaluri A, Wilding GE, Semler J. Inter-observer agreement for regional and whole gut transit measurement by wireless motility capsule in health, gastroparesis and constipation. Am J Gastroenterol. 2010;103:498-499.

33. Rankin G, Stokes M. Reliability of assessment tools in rehabilitation: an illustration of appropriate statistical analyses. Clin Rehabil. 1998;12:187-199.
34. Diaz Tartera HO, Webb DL, Al-Saffar AK, et al. Validation of SmartPill(R) wireless motility capsule for gastrointestinal transit time: intrasubject variability, software accuracy and comparison with video capsule endoscopy. Neurogastroenterol Motil. 2017;29:1-9.

35. Wald A, van Thiel DH, Hoechstetter L, et al. Gastrointestinal transit: the effect of the menstrual cycle. Gastroenterology. 1981;80:14971500.

36. Patcharatrakul T, Gonlachanvit S. Technique of functional and motility test: how to perform antroduodenal manometry. J Neurogastroenterol Motil. 2013;19:395-404.

37. Lin AY, Du P, Dinning PG, et al. High-resolution anatomic correlation of cyclic motor patterns in the human colon: evidence of a rectosigmoid brake. Am J Physiol Gastrointest Liver Physiol. 2017;312:G508G515.

38. Savarino E, Mei F, Parodi A, et al. Gastrointestinal motility disorder assessment in systemic sclerosis. Rheumatology (Oxford). 2013;52:1095-1100.

\section{SUPPORTING INFORMATION}

Additional Supporting Information will be found online in the supporting information tab for this article.

How to cite this article: Farmer $A D$, Wegeberg A-ML, Brock $B$, et al. Regional gastrointestinal contractility parameters using the wireless motility capsule: inter-observer reproducibility and influence of age, gender and study country. Aliment Pharmacol Ther. 2018;47:391-400. https://doi.org/10.1111/apt.14438 